\title{
Enzymatic response of ryegrass cellulose and hemicellulose valorization introduced by sequential alkaline extractions
}

\author{
Shao-Fei Sun ${ }^{1,2}$, Jing Yang ${ }^{1}$, Da-Wei Wang ${ }^{1}$, Hai-Yan Yang ${ }^{1,2^{*}}$, Shao-Ni Sun ${ }^{3 *}$ and Zheng-Jun Shi ${ }^{1,2^{*}}$
}

\begin{abstract}
Background: In view of the natural resistance of hemicelluloses in lignocellulosic biomass on bioconversion of cellulose into fermentable sugars, alkali extraction is considered as an effective method for gradually fractionating hemicelluloses and increasing the bioconversion efficiency of cellulose. In the present study, sequential alkaline extractions were performed on the delignified ryegrass material to achieve high bioconversion efficiency of cellulose and comprehensively investigated the structural features of hemicellulosic fractions for further applications.

Results: Sequential alkaline extractions removed hemicelluloses from cellulose-rich substrates and degraded part of amorphous cellulose, reducing yields of cellulose-rich substrates from 73.0 to $27.7 \%$ and increasing crystallinity indexes from 31.7 to $41.0 \%$. Alkaline extraction enhanced bioconversion of cellulose by removal of hemicelluloses and swelling of cellulose, increasing of enzymatic hydrolysis from 72.3 to $95.3 \%$. In addition, alkaline extraction gradually fractionated hemicelluloses into six fractions, containing arabinoxylans as the main polysaccharides and part of $\beta$-glucans. Simultaneously, increasing of alkaline concentration degraded hemicellulosic polysaccharides, which resulted in a decreasing their molecular weights from 67,510 to $50,720 \mathrm{~g} / \mathrm{mol}$.

Conclusions: The present study demonstrated that the sequential alkaline extraction conditions had significant effects on the enzymatic hydrolysis efficiency of cellulose and the investigation of the physicochemical properties of hemicellulose. Overall, the investigation the enzymatic hydrolysis efficiency of cellulose-rich substrates and the structural features of hemicelluloses from ryegrass will provide useful information for the efficient utilization of cellulose and hemicelluloses in biorefineries.
\end{abstract}

Keywords: Ryegrass, Cellulose, Hemicelluloses structure, Enzymatic hydrolysis, Alkaline extraction

\section{Background}

The global energy and financial crisis promote the development of renewable energies [1]. Bioethanol derived from lignocellulosic biomass is considered as an

\footnotetext{
*Correspondence: yanghaiyan@swfu.edu.cn; sunshaoni@126.com; shizhengjun1979@163.com

${ }^{1}$ Key Laboratory for Forest Resources Conservation and Utilization in the Southwest Mountains of China, Ministry of Education, Southwest Forestry University, Kunming 650224, China

3 Beijing Key Laboratory of Lignocellulosic Chemistry, Beijing Forestry University, Beijing 100083, China

Full list of author information is available at the end of the article
}

alternative energy to fossil oil due to its environmentally attractive and technologically feasible. Among the lignocelluloses, short rotation grasses are targeted as potential energy crops due to their abundance, availability, and high productivity [2-4]. In addition, grasses can be utilized as whole plants due to high percentage of total carbohydrates and comparatively less lignin content. Ryegrass is the most common bunch type of grass that widely used across the world as a forage and cover crop. The high abundance of ryegrass allows it to be a promising lignocellulosic feedstock for bioethanol production [5]. However, bioethanol production from grass is 
impeded by the recalcitrant structure of cell wall. Thus, an efficient pretreatment process is required to disrupt the intact structure of biomass and release carbohydrate polymers for further fermentation $[3,4]$.

Pretreatment of lignocelluloses is the process which removes hemicelluloses and lignin, reduces cellulose crystallinity, and increases accessibility of material for enzymes [6,7]. The hemicelluloses in the plant cell wall have an inhibitory effect on the enzymatic hydrolysis of cellulose, since this component covers the cellulose microfibers and further forms a physical barrier to prevent the entry of enzymes [8]. Lignin can not only form a shielding layer, but also can non-productively and irreversibly adsorb cellulase, resulting in a very low enzymatic hydrolysis rate of cellulose $[9,10]$. Among the pretreatment technologies, alkaline pretreatment is one of the major chemical pretreatments due to practical advantages such as low reaction temperature and pressure, no need for complicated reactors [11]. Up to now, alkaline pretreatment has been widely applied on lignocellulosic biomass with low lignin contents, such as agricultural wastes, herbaceous crops, and hardwoods. During alkaline pretreatment, hydrogen and covalent bonds (such as ester and ether bonds) are broken, resulting in alteration of lignin structure and disruption of crosslinks between hemicelluloses and other components [12]. The cleavage of these linkages facilitates dissociation of entire cell wall of lignocelluloses and solubilization of hemicelluloses and lignin, improving accessibility of lignocellulose. In addition, more hemicelluloses are dissolved during the alkaline pretreatment as compared to lignin and cellulose [13]. The removal of hemicelluloses is often correlated well with the increase of enzymatic hydrolysis of lignocellulosic biomass. Although hemicelluloses can be hydrolyzed into its component sugars, the pentoses, such as xylose and arabinose, in hemicelluloses are difficult to ferment to ethanol because of the lack of the natural microorganisms that metabolize xylose or arabinose [14]. Thus, hemicelluloses can be recovered by alkaline treatment for further utilization.

Hemicelluloses, the second most abundant structural polymers in lignocellulosic biomass, contain different types of sugars according to plant resources. Generally, glucouronoxylan (xylan) is found to be the principal constituent of the hemicelluloses in hardwood and agriculture residues, while galactoglucomannan is the principal component of softwood hemicelluloses [15-17]. Different from cellulose, hemicelluloses are branched heteropolysaccharides of several different neutral and acidic monosaccharides [18]. Apart from origin of hemicelluloses, extraction methods also affect the properties of hemicelluloses. Among different hemicelluloses extraction methods, alkaline and hot water extractions are the most popular processes. After extraction, the obtained hemicelluloses can used directly as natural polymers in industries or used as feedstock for producing platform chemicals [18]. For instance, the hemicelluloses can be partially hydrolyzed to produce xylo-oligosaccharides (XOS), which is considered as a prebiotic and widely used in health products due to its ability to improve the calcium absorption, reduce the cholesterol, promote the growth of probiotics, and lower the risk of colon cancer $[19,20]$.

In this study, cellulose-rich substrates and hemicellulosic fractions of ryegrass were gradually recovered by sequential alkaline extractions from delignified material. The effects of sequential alkaline treatments on chemical compositions and structural characteristics of the samples were analyzed by sugar analysis, Fourier transform infrared (FT-IR), and nuclear magnetic resonance (NMR) spectroscopy, respectively. In addition, the effect of sequential alkaline treatments on enzymatic hydrolysis of cellulose-rich substrate was also evaluated.

\section{Results and discussion \\ Yields and chemical compositions of cellulose-rich substrates}

Hemicellulosic compounds mutually adhered with cellulose microfibrils by hydrogen bonds and van der Waals forces, holding the stiff cellulose fibrils in place. However, hemicelluloses have been considered as major obstacle of physically penetrating and attacking the cellulose by cellulase in bioconversion process [21]. Aqueous alkaline treatment has been considered as an efficient process for hemicelluloses extraction. Yields and chemical compositions of cellulose-rich substrates obtained from sequential alkaline extractions are shown in Table 1. Cellulose-rich substrate $\left(\mathrm{R}_{\text {pulp }}\right)$ obtained by delignification contained $47.8 \%$ glucan as the major sugar. Hemicellulosic compounds, including xylan (19.7\%), arabinan (7.7\%), galactan (2.6\%), mannan $(0.1 \%)$, galacturonic acid $(2.3 \%)$, and glucuronic acid $(0.3 \%)$, totally accounted $32.7 \%$ of the substrate. The chemical compositions of hemicellulosic compounds in delignified ryegrass indicated that arabinoxylans was the main compound of hemicellulosic fractions. This result was consistent with the chemical compositions of hemicellulosic fractions obtained from sequential alkaline extractions. Besides, 3.2\% Klason lignin and $0.7 \%$ acid-soluble lignin were remained in the cellulose-rich substrate. After alkaline extraction, part of the hemicellulosic compounds and lignin were removed. As the alkaline concentration increased from 0.15 to $2.5 \%$, the yields of solid cellulose-rich substrates also decreased from 73.0 to $27.7 \%$. The contents of hemicellulosic compounds and lignin decreased from 30.3 to $19.2 \%$, and from 2.3 to $0.7 \%$, respectively. The 
Table 1 Yields and chemical components of cellulose-rich substrates obtained from sequential alkaline extractions of delignified ryegrass

\begin{tabular}{|c|c|c|c|c|c|c|c|c|c|c|}
\hline \multirow[t]{2}{*}{ Samples } & \multirow[t]{2}{*}{ Yield ${ }^{a, c}(\%)$} & \multicolumn{9}{|c|}{ Substrates composition ${ }^{b, c}(\%)$} \\
\hline & & Ara & Gal & Glu & Xyl & Man & GalA & GluA & $\mathrm{KL}$ & ASL \\
\hline$R_{\text {pulp }}$ & $100.0 \pm 0.6$ & $7.7 \pm 0.2$ & $2.6 \pm 0.0$ & $47.8 \pm 1.5$ & $19.7 \pm 0.6$ & $0.1 \pm 0.0$ & $2.3 \pm 0.0$ & $0.3 \pm 0.0$ & $3.2 \pm 0.1$ & $0.7 \pm 0.0$ \\
\hline $\mathrm{R}_{0.15 \%}$ & $73.0 \pm 3.3$ & $7.1 \pm 0.2$ & $1.8 \pm 0.0$ & $51.1 \pm 1.7$ & $18.2 \pm 0.6$ & $0.1 \pm 0.0$ & $2.7 \pm 0.0$ & $0.4 \pm 0.0$ & $1.8 \pm 0.0$ & $0.5 \pm 0.0$ \\
\hline $\mathrm{R}_{0.3 \%}$ & $68.9 \pm 3.2$ & $6.6 \pm 0.2$ & $1.2 \pm 0.0$ & $52.7 \pm 1.6$ & $17.7 \pm 0.5$ & $0.1 \pm 0.0$ & $2.4 \pm 0.0$ & $0.3 \pm 0.0$ & $1.8 \pm 0.0$ & $0.4 \pm 0.0$ \\
\hline $\mathrm{R}_{0.5 \%}$ & $63.9 \pm 2.9$ & $5.1 \pm 0.1$ & $1.2 \pm 0.0$ & $54.7 \pm 1.8$ & $17.0 \pm 0.5$ & $0.1 \pm 0.0$ & $2.1 \pm 0.0$ & $0.2 \pm 0.0$ & $1.7 \pm 0.0$ & $0.4 \pm 0.0$ \\
\hline $\mathrm{R}_{1.0 \%}$ & $58.4 \pm 2.6$ & $4.3 \pm 0.1$ & $1.0 \pm 0.0$ & $57.9 \pm 1.8$ & $16.7 \pm 0.5$ & $0.2 \pm 0.0$ & $0.5 \pm 0.0$ & $0.2 \pm 0.0$ & $1.6 \pm 0.0$ & $0.3 \pm 0.0$ \\
\hline $\mathrm{R}_{1.5 \%}$ & $50.8 \pm 2.4$ & $3.8 \pm 0.1$ & $1.0 \pm 0.0$ & $59.0 \pm 1.8$ & $16.1 \pm 0.5$ & $0.2 \pm 0.0$ & $0.4 \pm 0.0$ & $0.2 \pm 0.0$ & $0.9 \pm 0.0$ & $0.3 \pm 0.0$ \\
\hline $\mathrm{R}_{2.5 \%}$ & $27.7 \pm 1.3$ & $3.3 \pm 0.1$ & $0.8 \pm 0.0$ & $62.2 \pm 2.0$ & $14.3 \pm 0.4$ & $0.2 \pm 0.0$ & $0.4 \pm 0.0$ & $0.2 \pm 0.0$ & $0.4 \pm 0.0$ & $0.3 \pm 0.0$ \\
\hline
\end{tabular}

a Yields of cellulose-rich substrates obtained from the delignified ryegrass by sequential alkaline extractions, calculated as [(the weight of cellulose-rich substrate obtained after each alkaline extraction)/(the weight of the delignified ryegrass used for sequential alkaline extractions)] $\times 100 \%$;

b Ara, arabinan; Gal, galactan; Glu, glucan; Xyl, xylan; Man, mannan; GalA, galacturonic acid; GluA, glucuronic acid; ASL, acid-soluble lignin; KL, Klason lignin

c The values are mean \pm SD of three parallel determinations

residual hemicelluloses in substrates were xylans, which were the main compounds, and their contents decreased from 18.2 to $14.3 \%$. The solubilization of hemicellulosic fractions was accompanied with increase of cellulose contents from 51.1 to $62.2 \%$. Increasing of cellulose content is usually preferred for ethanol production due to the direct proportional relationship of ethanol yield and cellulose content of substrate [22]. These results were similar with the composition analysis of cellulosic samples obtained from sequential $\mathrm{NaOH}$ extractions of oat straw holocellulose [23]. However, a less amount of glucan in cellulose-rich substrate was observed after alkaline extraction in this study. It might be ascribed to the lower extraction temperature performed in this study. Besides, the dilute acid pretreatment of sugarcane bagasse before alkaline extraction also largely removes hemicellulosic fraction and releases higher content of cellulose in solid fraction than which in ryegrass cellulosic substrates [24].

\section{FT-IR spectra analysis of cellulose-rich substrates}

Under alkaline condition, the ester linkages in lignocellulose can be cleaved at relatively high temperature [25]. IR spectroscopy is a widely used to determine functional groups of complex polymers. FT-IR spectra of cellulose-rich substrates are shown in Fig. 1. The stretching vibration of $-\mathrm{OH}$ groups in substrates is observed at $3397 \mathrm{~cm}^{-1}$. The bands at about 1319, 1245, and $1206 \mathrm{~cm}^{-1}$ are due to the in-plane bending of $-\mathrm{OH}$. The bands at 2910 and $1379 \mathrm{~cm}^{-1}$ are assigned to $\mathrm{C}-\mathrm{H}$ stretching and $\mathrm{C}-\mathrm{H}$ bending along the chain, respectively. The intense absorption band at $1630 \mathrm{~cm}^{-1}$ corresponds to the bending mode of the absorbed water. The attributions of the main adsorptions are characteristic of glycosidic structures at $1171,1110,1060$, and $1035 \mathrm{~cm}^{-1}$ for antisymmetric bridge $\mathrm{C}-\mathrm{O}-\mathrm{C}$ and $\mathrm{C}-\mathrm{O}$ stretching, respectively.

A small band at about $899 \mathrm{~cm}^{-1}$ in the spectra is characteristic of $C_{1}$ group of frequency/antisymmetric outof-plane ring stretching due to $\beta$-glycosidic linkages. Although the spectral pattern of the samples was similar, the band $\left(1725 \mathrm{~cm}^{-1}\right)$ assigned for $\mathrm{C}=\mathrm{O}$ stretching of acetyl groups in the spectrum of delignified ryegrass $\left(\mathrm{R}_{\text {pulp }}\right)$ disappeared in the spectra of samples after alkaline extraction. This result indicated the deacetylation of the substrates under alkaline conditions. Pretreatment of corn stalk with $0.5 \% \mathrm{KOH}$ solution at $30{ }^{\circ} \mathrm{C}$ for $24 \mathrm{~h}$ also obtains $91.34 \%$ deacetylation [26]. The disappearance of ester bonds in FT-IR spectra is consisted with the results observed in solid NMR spectra of celluloserich substrates (Fig. 2). In addition, the signal at around $1539 \mathrm{~cm}^{-1}$ in spectrum of $R_{\text {pulp }}$ is assigned to the residual lignin (3.9\%) in ryegrass holocellulose.

\section{Crystallinity analysis of cellulose-rich substrates}

Solid-state NMR methodologies are particularly useful for studying structural characteristics of lignocellulose and individual plant cell wall components due to the fact that they can provide much chemical information and ultrastructural details [27]. ${ }^{13} \mathrm{C} \mathrm{CP} / \mathrm{MAS}$ is one of the modern solid-state NMR methodologies; it can be used for a qualitative identification of the main chemical and structural changes taking place in the samples as a consequence of the pretreatments. CP/MAS spectra of cellulose-rich substrates obtained from sequential alkaline extractions are shown in Fig. 2. The signals between 60 and $110 \mathrm{ppm}$ are singled to carbohydrates. The signal at about $105 \mathrm{ppm}$ origins from $\mathrm{C}_{1}$ groups of cellulose. The overlapping signals in the region of $70-80 \mathrm{ppm}$ are assigned to $\mathrm{C}_{2}, \mathrm{C}_{3}$, and $\mathrm{C}_{5}$ of cellulose. In the spectra of 


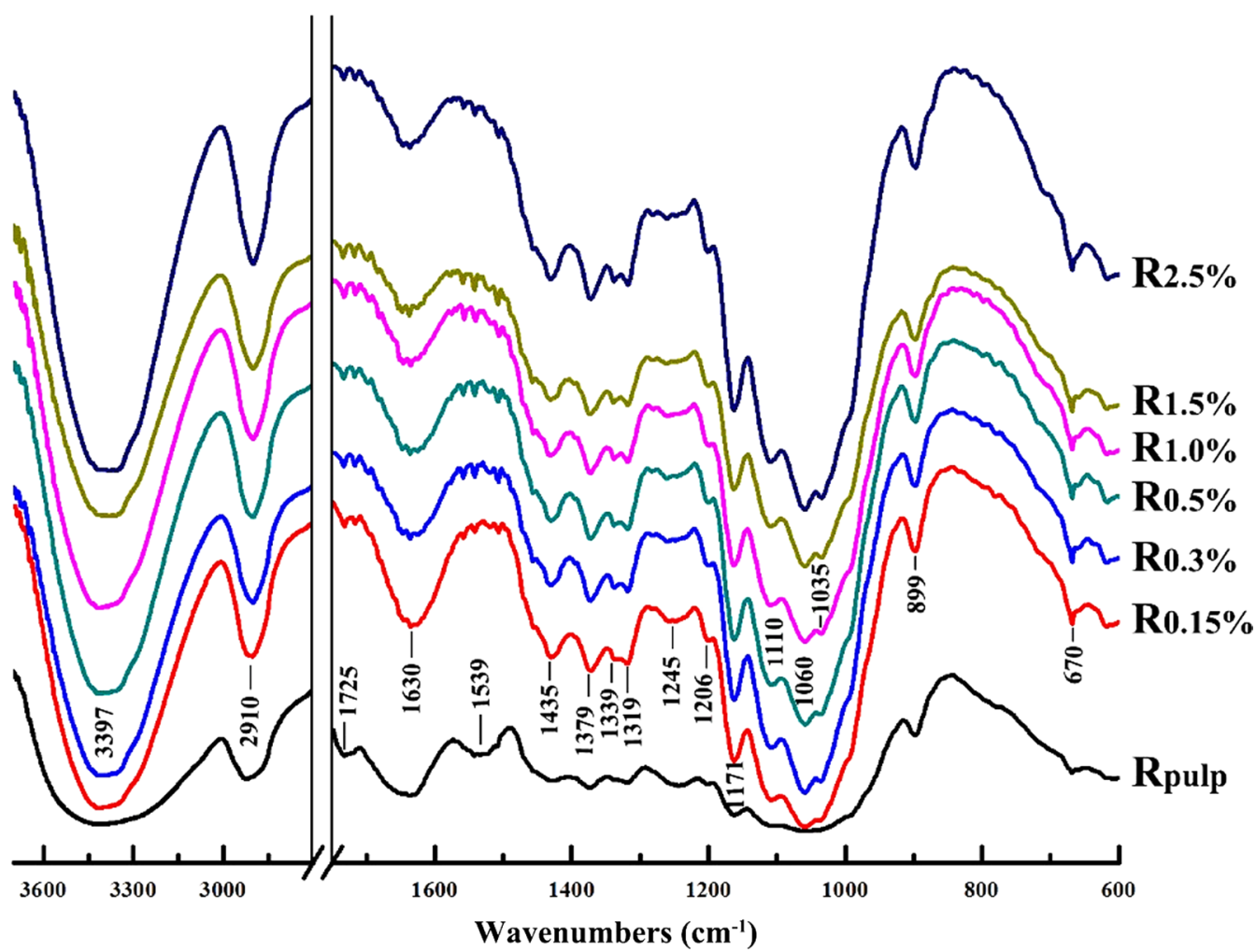

Fig. 1 FT-IR spectra of the delignified ryegrass $\left(R_{\text {pulp }}\right)$ and the cellulose-rich substrates $\left(R_{0.15 \%}, R_{0.3 \%}, R_{0.5 \%}, R_{1.0 \%}, R_{1.5 \%}\right.$, and $\left.R_{2.5 \%}\right)$ obtained by sequential alkaline treatments of the delignified ryegrass

cellulose, the amorphous carbons of $\mathrm{C}_{4}$ are represented by a fairly broad signal from 80 to $85 \mathrm{ppm}$, while crystalline carbons of $\mathrm{C}_{4}$ generate a sharper resonance from 85 to $92 \mathrm{ppm}$. Two phases of $\mathrm{C}_{6}$ cellulose are found at about 63 and $69 \mathrm{ppm}$, respectively. The peaks around 21 and $172 \mathrm{ppm}$ in the spectrum of $\mathrm{R}_{\text {pulp }}$ origin for methyl and carboxylic carbons of acetyl groups attached to the hemicellulosic fractions. After alkaline extraction, the disappearance of these peaks in the spectra of cellulose-rich substrates indicated the cleavage of bonds between acetyl groups and backbone during alkaline extraction.

Crystallinity index (CrI) is an important characteristic affecting the enzymatic hydrolysis of cellulose. The $\mathrm{C}_{4}$ peak in the carbon spectrum of cellulose is the most commonly utilized peak used to extract ultrastructural information, such as crystalline domains [28]. During the alkaline treatment, alkali molecule can penetrate into the cellulose macromolecule and disrupt the hydrogen bonds between intra- and inter-molecule chains, thereby changing the ultrastructure of cellulose. The effects of sequential alkaline extractions on ordered structure of cellulose are shown as crystallinity index in CP/MAS spectra, which are calculated as the peak area ratio of crystalline to total of $\mathrm{C}_{4}$ signals. After alkaline extraction, the peak intensity for amorphous cellulose decrease, introducing an increase of cellulose-rich substrates crystallinity index (31.7, 33.8, 35.7, 39.1, and 41.0\%). The increment of crystallinity index of cellulose was ascribed to the fact that alkaline treatments resulted in greater hydrolyzation of amorphous regions than crystalline regions and peeling reaction of the amorphous regions in cellulose [11]. In addition, an increase of crystalline index of the cellulose residue was also due to the removal of amorphous hemicelluloses from the pulp.

\section{Enzymatic hydrolysis of cellulose-rich substrates}

Hemicelluloses are considered as physical barriers for enzyme to attack cellulosic substrate. The effects of fractional removal of hemicellulosic polymers on enzymatic hydrolysis of cellulose-rich substrates are shown in Fig. 3. The delignified ryegrass achieved $59.0 \%$ cellulose conversion rate by enzymatic hydrolysis in first $3 \mathrm{~h}$ and $72.3 \%$ final glucose conversion in $48 \mathrm{~h}$. The enzymatic conversion of cellulose was further enhanced by removal of hemicellulosic polymers. With the decrease content of hemicelluloses in substrates from 32.7 to $19.2 \%$, the glucose yields of enzymatic hydrolysis increased gradually from 59.0 to $74.5 \%$ and 72.3 to $95.3 \%$, respectively. The 


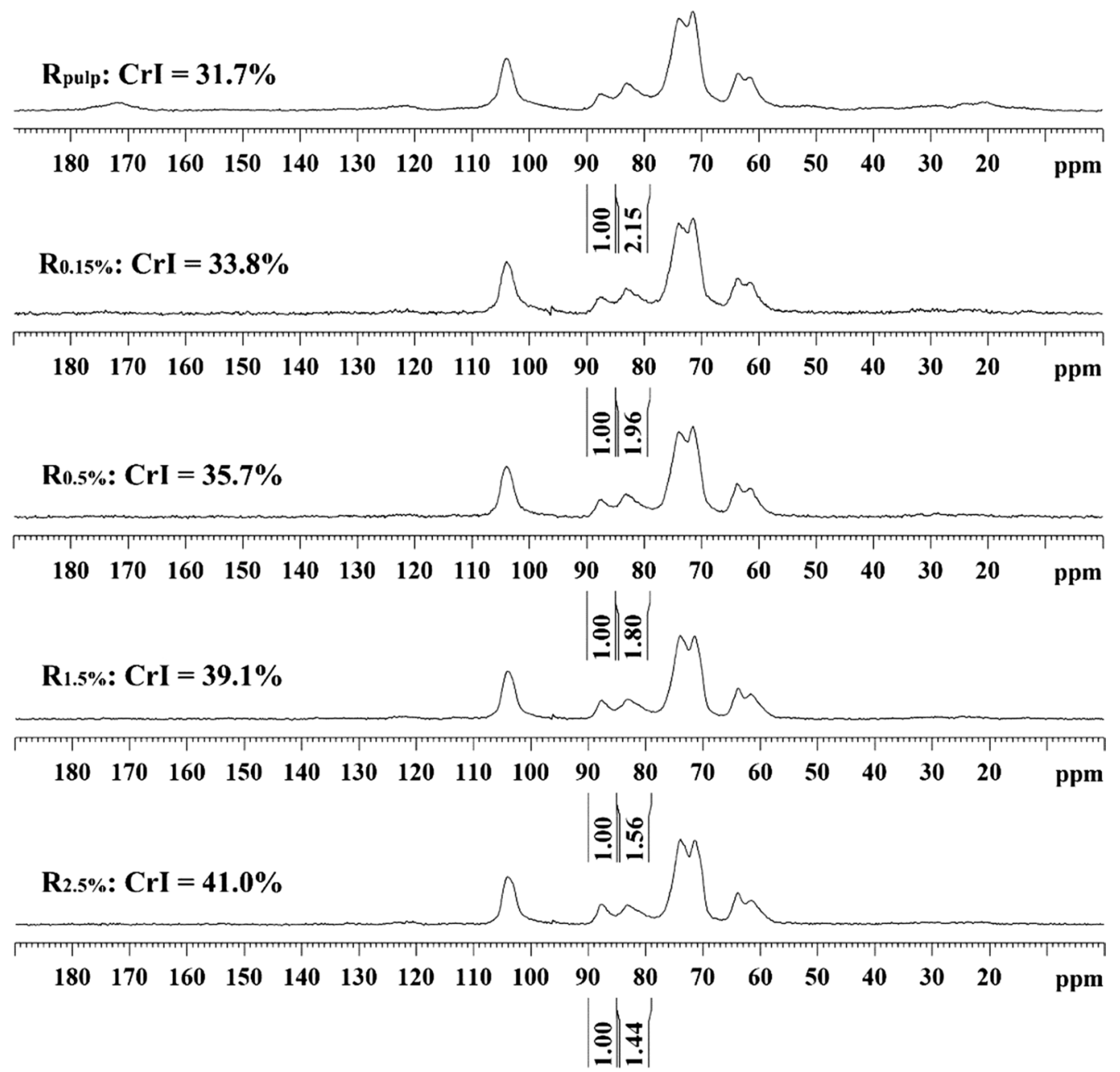

Fig. 2 CP/MAS ${ }^{13} C$-NMR spectra of the delignified ryegrass $\left(R_{\text {pulp }}\right)$ and the cellulose-rich substrates $\left(R_{0.15 \%}, R_{0.5 \%}, R_{1.5 \%}\right.$, and $\left.R_{2.5 \%}\right)$ obtained by sequential alkaline treatments of the delignified ryegrass

increase of initial enzymatic conversion was ascribed to the fact that sequential alkaline treatments removed hemicelluloses and increased accessibility of material [6]. $\mathrm{NaOH}$ pretreatment of Napier grass removes $84 \%$ lignin and achieves $94 \%$ glucan conversion rate by enzymatic hydrolysis [29]. Pretreatment with ryegrass and surfactant also improves the enzymatic conversion and achieves $87 \%$ reducing sugar yield as the maximum [30]. The high glucose yield in this study may be ascribed to the fact that sequential alkaline extraction not only removed hemicelluloses, but also swelled cellulose macromolecule. Swelling of biomass also occurs during alkaline pretreatment of rice husk with $2 \% \mathrm{NaOH}$ [31]. However, the successively extracted poplar holocellulose has also yielded an increment of cellulose enzymatic conversion and achieved $61.9 \%$ cellulose conversion as the maximum [23]. This higher glucose conversion of ryegrass may be ascribed to the structure difference of these two materials.

\section{Yields, chemical compositions, and molecular weights of hemicellulosic fractions}

Hydroxyl ions can swell of cellulose, disrupt intermolecular hydrogen bonds between cellulose and hemicelluloses, and dissolve hemicelluloses. Thus, alkaline extraction is one of the most efficient methods for isolation of hemicellulosic polymers [32]. Besides, alkaline extraction can gradually recover hemicellulosic polymers from lignocellulosic materials depending on components and molecular weights [33]. Yields, chemical compositions, and molecular weights of hemicellulosic fractions are shown in Tables 2 and 3. Sequential alkaline extractions of delignified ryegrass with $0.15,0.3,0.5,1.0,1.5$, and $2.5 \% \mathrm{KOH}$ solution recovered $7.3,5.8,33.9,13.9,11.3$, and $8.7 \%$ 


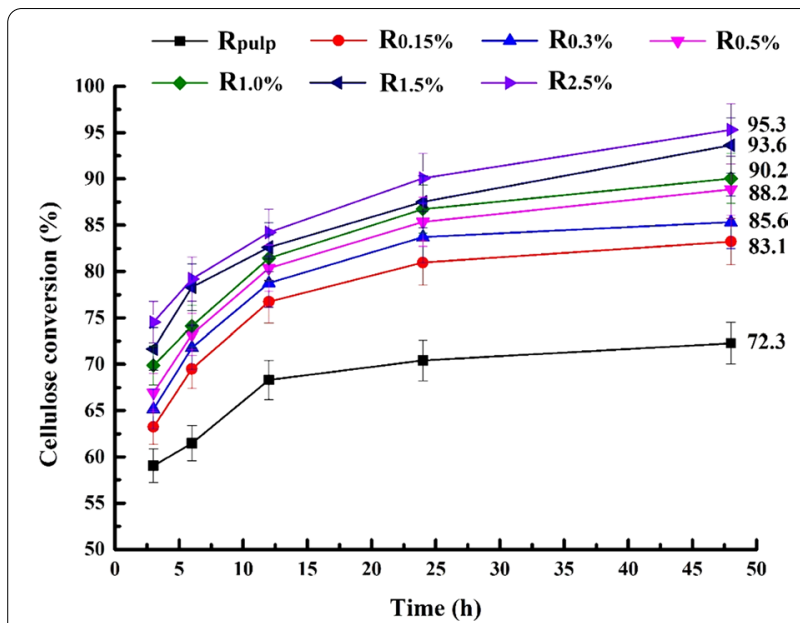

Fig. 3 Glucose yields of enzymatic hydrolysis of the delignified ryegrass $\left(R_{\text {pulp }}\right)$ and the cellulose-rich substrates $\left(R_{0.15 \%}, R_{0.3 \%}, R_{0.5 \%}\right.$ $R_{1.0 \%}, R_{1.5 \%}$ and $R_{2.5 \%}$ ) obtained by sequential alkaline treatments of the delignified ryegrass

hemicelluloses, respectively, equal to $80.9 \%$ of total hemicelluloses in holocellulose. It can be seen that the yields of hemicelluloses increased with increasing of alkaline concentration from 0.15 to $0.5 \%$. This result suggested that most hemicelluloses were recovered in the early part of the alkaline extraction procedure. However, a continuous increase of alkali concentration to $2.5 \%$ declined yields to $8.7 \%$. This result indicated the degradation of hemicellulosic fractions under alkaline condition, which was consisting with molecular weight of hemicellulosic fractions.

The monosaccharide in hemicellulosic polymers is always determined by the neutral sugars and uronic acids released during the acid hydrolysis. Hemicelluloses in ryegrass were fractionated into six fractions by sequential alkaline extractions. It can be seen that xylose was the major neutral sugar of the six hemicellulosic fractions followed by arabinose, glucose, and galactose. Mannose, glucuronic acid, and galacturonic acid were found to be minor amount components in hemicelluloses. As the increase of alkaline concentration, the contents of xylose increased from 45.1 to $62.5 \%$, accompanying with the decrease contents of arabinose and galactose from 29.4 to $18.3 \%$, and from 9.4 to $3.9 \%$, respectively. These phenomena suggested that xylan was the backbone of ryegrass hemicelluloses. Arabinose and minor quantity of uronic acids might substitute on the backbone of xylan as side chains. Besides, the ratio of arabinose to xylose decreased from 0.65 to 0.29 , indicating that the linkages between side chains and backbone were cleaved under the alkaline concentration. In addition, glucose was found to be in the third large amount of neutral sugars and its content decreased from 10.3 to $3.7 \%$ as alkaline concentration increased from 0.15 to $1.0 \%$. It revealed that $\beta$-glucan was one of polysaccharides in ryegrass hemicelluloses. However, a further increase of alkaline concentration resulted in an increase of glucose concentration in hemicelluloses. This result might be ascribed the fact that cellulose was degraded during $1.5 \%$ and $2.5 \% \mathrm{KOH}$ extractions. An increment of glucose content in hemicelluloses with increasing of alkaline concentration is also observed in the research of alkaline extraction of Caragana korshinskii Kom [34].

Molecular mass is an important parameter which affects physicochemical properties of hemicelluloses. Generally, the molecularly uniformed polysaccharides always have polymerization degrees in excess of 50 and polydispersity below 3 [35]. Table 3 shows the weightaverage $\left(M_{w}\right)$ and number-average molecular weights $\left(M_{n}\right)$ and polydispersity values $\left(M_{w} / M_{n}\right)$ of six alkaline

Table 2 Yields and sugar compositions (relative \%, w/w) of hemicellulosic fractions obtained from sequential alkaline extractions of delignified ryegrass

\begin{tabular}{|c|c|c|c|c|c|c|c|c|}
\hline \multirow[t]{2}{*}{ Samples } & \multirow[t]{2}{*}{ Yield ${ }^{a, c}(\%)$} & \multicolumn{7}{|c|}{ Sugar composition ${ }^{b, c}$ (relative $\%$ ) } \\
\hline & & Ara & Gal & Glu & Xyl & Man & GluA & GalA \\
\hline $\mathrm{H}_{0.15 \%}$ & $7.3 \pm 0.3$ & $29.4 \pm 0.9$ & $9.4 \pm 0.3$ & $10.3 \pm 0.3$ & $45.1 \pm 1.5$ & $1.1 \pm 0.0$ & $2.7 \pm 0.0$ & $2.0 \pm 0.0$ \\
\hline $\mathrm{H}_{0.3 \%}$ & $5.8 \pm 0.2$ & $29.8 \pm 1.0$ & $10.2 \pm 0.3$ & $8.8 \pm 0.2$ & $46.2 \pm 1.5$ & ND & $2.0 \pm 0.0$ & $3.0 \pm 0.1$ \\
\hline $\mathrm{H}_{0.5 \%}$ & $33.9 \pm 1.6$ & $28.6 \pm 0.9$ & $10.3 \pm 0.3$ & $7.8 \pm 0.2$ & $48.1 \pm 1.5$ & $1.0 \pm 0.0$ & $2.5 \pm 0.0$ & $1.6 \pm 0.0$ \\
\hline $\mathrm{H}_{1.0 \%}$ & $13.9 \pm 0.6$ & $29.0 \pm 0.9$ & $8.4 \pm 0.2$ & $3.7 \pm 0.1$ & $52.8 \pm 1.6$ & $1.1 \pm 0.0$ & $1.8 \pm 0.0$ & $3.2 \pm 0.1$ \\
\hline $\mathrm{H}_{1.5 \%}$ & $11.3 \pm 0.5$ & $22.7 \pm 0.7$ & $6.4 \pm 0.2$ & $12.8 \pm 0.4$ & $54.2 \pm 1.7$ & ND & $1.0 \pm 0.0$ & $2.9 \pm 0.0$ \\
\hline $\mathrm{H}_{2.5 \%}$ & $8.7 \pm 0.4$ & $18.3 \pm 0.6$ & $3.9 \pm 0.1$ & $13.5 \pm 0.4$ & $62.5 \pm 2.1$ & ND & $0.6 \pm 0.0$ & $1.2 \pm 0.0$ \\
\hline
\end{tabular}

a Yields of the hemicelluloses, calculated as [(the weight of the hemicelluloses obtained in each alkaline extraction)/(the weight of the hemicelluloses in the delignified ryegrass)] $\times 100 \%$;

b Ara, arabinose; Gal, galactose; Glu, glucose; Xyl, xylose; Man, mannose; GalA, galacturonic aicd; GluA, glucuronic aicd; ND, not detected

c The values are mean \pm SD of three parallel determinations 
Table 3 Weight-average molecular weights $\left(M_{w}\right)$ and numberaverage molecular weights $\left(M_{n}\right)(\mathrm{g} / \mathrm{mol})$, and polydispersity $\left(M_{w}\right.$ $M_{n}$ ) of hemicellulosic fractions isolated by sequential alkaline extractions of delignified ryegrass

\begin{tabular}{llll}
\hline Samples $^{\mathrm{a}}$ & $M_{w}{ }^{\mathrm{b}}$ & $M_{n}{ }^{\mathrm{b}}$ & $M_{w} / M_{n}$ \\
\hline $\mathrm{H}_{0.15 \%}$ & $67,510 \pm 3038$ & $39,670 \pm 1786$ & 1.70 \\
$\mathrm{H}_{0.3 \%}$ & $61,480 \pm 2829$ & $37,040 \pm 1704$ & 1.66 \\
$\mathrm{H}_{0.5 \%}$ & $55,460 \pm 2219$ & $28,730 \pm 1150$ & 1.93 \\
$\mathrm{H}_{1.0 \%}$ & $52,120 \pm 2242$ & $25,930 \pm 1115$ & 2.01 \\
$\mathrm{H}_{1.5 \%}$ & $51,420 \pm 2366$ & $24,660 \pm 1135$ & 2.09 \\
$\mathrm{H}_{2.5 \%}$ & $50,720 \pm 2283$ & $22,480 \pm 1012$ & 2.26 \\
\hline
\end{tabular}

a Corresponding to the hemicellulosic fractions in Table 2

b Molecular weights values $\left(M_{w}\right.$ and $\left.M_{n}\right)$ are mean \pm SD of three parallel determinations

hemicelluloses from ryegrass. The $M_{w}$ of hemicellulosic fractions gradually decreased from 67,510 to $52,120 \mathrm{~g} /$ $\mathrm{mol}$ as the alkaline concentration rose from 0.15 to $1.0 \%$. It indicated that polysaccharides were degraded under the alkaline condition with the increase of the alkaline concentrations. The polydispersity indexes of hemicelluloses ranged from 1.66 to 2.01 , implying a structural homogeneity of all hemicellulosic fractions.
Further increase of $\mathrm{KOH}$ concentration to $1.5 \%$ and $2.5 \%$ degraded both hemicelluloses and amorphous cellulose. The co-participation of cellulose fragments and hemicellulosic polysaccharides introduced a slight increase of polydispersity indexes of hemicelluloses from 2.09 to 2.26 .

\section{FT-IR spectra analysis of hemicellulosic fractions}

FT-IR spectra of hemicellulosic fractions are shown in Fig. 4. The spectra are dominant by signals at 3413 and $2935 \mathrm{~cm}^{-1}$ due to stretching vibration of $-\mathrm{OH}$ and $\mathrm{C}-\mathrm{H}$, respectively. The peaks for $\mathrm{O}-\mathrm{H}$ in-plane bending occur at 1317,1257 , and $1215 \mathrm{~cm}^{-1}$, while $\mathrm{O}-\mathrm{H}$ out-of-plane bending is observed at $659 \mathrm{~cm}^{-1}$. The signals originate from $\mathrm{C}-\mathrm{O}$ stretching is distributed in the range of $1200-950 \mathrm{~cm}^{-1}$, which are fingerprint region of hemicellulosic polysaccharides. The prominent band at $1049 \mathrm{~cm}^{-1}$ is attributed to the $\mathrm{C}-\mathrm{O}, \mathrm{C}-\mathrm{C}$ stretching, or $\mathrm{C}-\mathrm{OH}$ bending typical of xylans. The shoulder band at $899 \mathrm{~cm}^{-1}$ is attributed to the $\beta$-linkages of hemicelluloses skeleton. All spectra of hemicelluloses showed similarities in this region, which was consistent with similar sugar components detected in hemicellulosic fractions (Table 2). The massive hydroxyl groups give

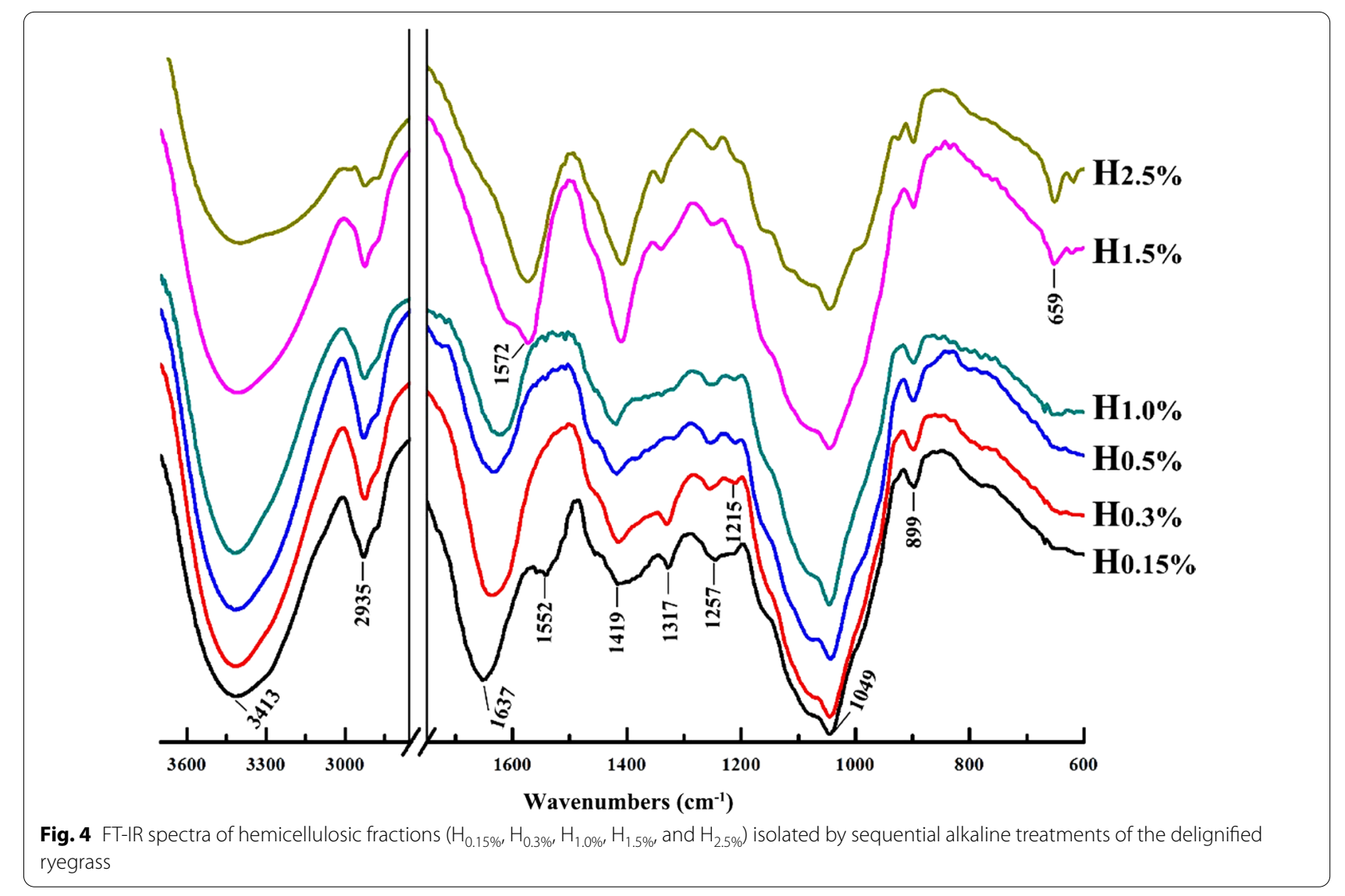


hemicellulosic polysaccharides strong affinity for water. The band at $1637 \mathrm{~cm}^{-1}$ is assigned to the absorption of water on hemicelluloses. The signal at $1419 \mathrm{~cm}^{-1}$ is evidence for symmetric stretching of anion carboxylate, originating from salt state of the uronic acids side chain. Besides, the peak at $1552 \mathrm{~cm}^{-1}$ in spectrum of $\mathrm{H}_{0.15 \%}$ has a contribution from the associated lignin. However, this absorbance disappeared in spectra of the hemicellulosic fractions obtained from further steps of the alkali extraction with the increasing its concentrations. This result is consistent with the signal for lignin observed in the spectra of cellulose-rich substrates. These phenomena were ascribed the fact that hemicelluloses associated with lignin through chemical bonds and form lignin-carbohydrate complexes (LCC) in plant cell wall [36]. Alkali can effectively cleave the linkages in LCC and promote the dissolution of hemicelluloses. The associated lignin was also determined in the alkali-soluble hemicelluloses from delignified peashrub [37].

\section{NMR spectra analysis of hemicellulosic fractions}

NMR is an efficient technology to assay and identify the backbone and type of sidechain of polymers. The structural characteristics of hemicellulosic fractions were elucidated by ${ }^{13} \mathrm{C}$ and HSQC NMR, and are illustrated in Figs. 5 and 6 , respectively. The assignment data of HSQC NMR spectra are given in Table 4. The signals for ${ }^{13} \mathrm{C}$-NMR were assigned on the basis of the HSQC spectra and a previous literature [38]. The signals of different structural sugars are overlapped in the ${ }^{13} \mathrm{C}$-NMR spectra. The signals at $102.2,76.1,74.6,73.6$, and $63.3 \mathrm{ppm}$ correspond to $\mathrm{C}_{1}, \mathrm{C}_{4}, \mathrm{C}_{3}, \mathrm{C}_{2}$, and $\mathrm{C}_{5}$ of $\beta$-(1-4)-linked-D-Xylp units, respectively. The signals for $\mathrm{C}_{1}-\mathrm{C}_{5}$ of arabinose appeared at 109.4, 80.2, 78.5, 86.4 , and $61.7 \mathrm{ppm}$, respectively. The signals observed at $173.3,82.6,72.3$, and $59.7 \mathrm{ppm}$ are originated from the $\mathrm{C}_{6}, \mathrm{C}_{4}, \mathrm{C}_{5}$ and methoxyl group of 4-O-methyl-D-glucuronic acid, respectively. However, the $\mathrm{C}_{6}$ of dissociative glucuronic acid was observed at $181.6 \mathrm{ppm}$. The present of $\beta$-glucans in hemicelluloses was identified by the signals at $80.3 \mathrm{ppm}\left(\mathrm{C}_{3}\right)$ and $60.6 \mathrm{ppm}$. The occurrence of galactose was observed as the signal at $69.0 / 3.88 \mathrm{ppm}$ in HSQC of spectra. These results implied that the alkaline extract hemicelluloses from ryegrass presumably composed of galactoarabinoxylans, L-arabino-(4-O-methylD-glucurono)xylans, and $\beta$-glucans. The results are consisting with structural sugar composition analysis and previous studies $[39,40]$.

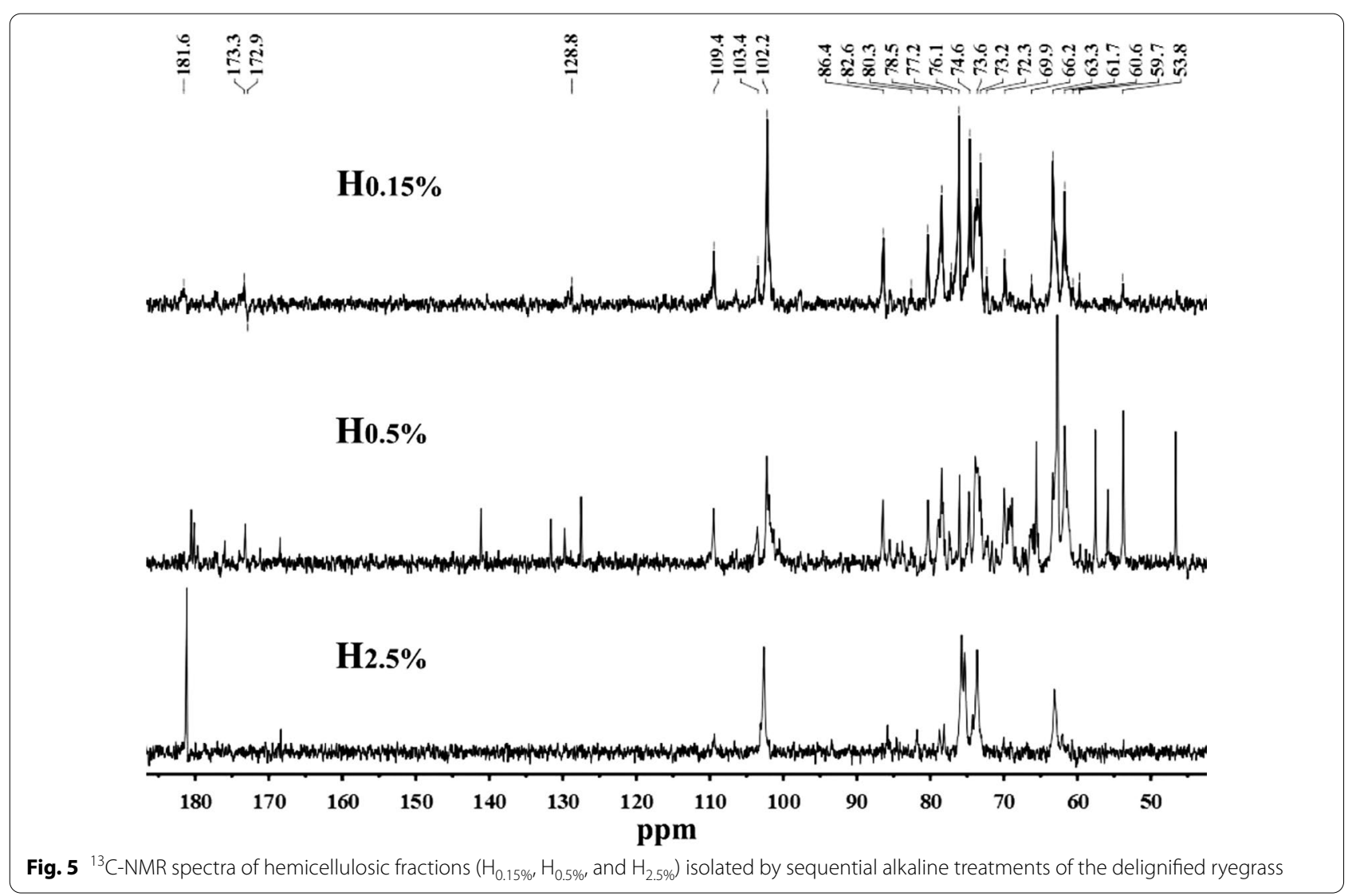



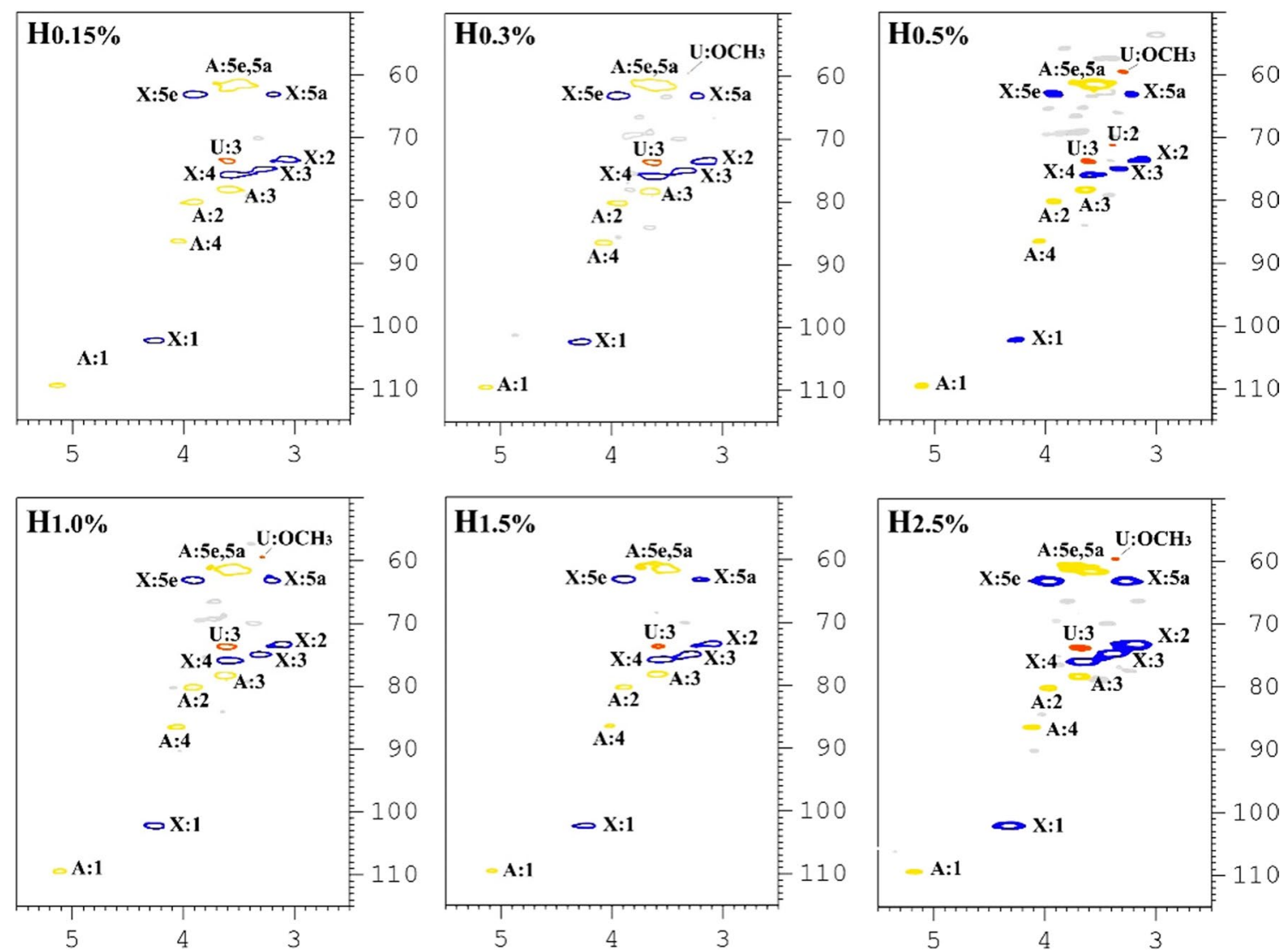

Fig. 6 2D-HSQC NMR spectra of hemicellulosic fractions $\left(\mathrm{H}_{0.15 \%}, \mathrm{H}_{0.3 \%}, \mathrm{H}_{0.5 \%}, \mathrm{H}_{1.0 \%}, \mathrm{H}_{1.5 \%}\right.$, and $\left.\mathrm{H}_{2.5 \%}\right)$ isolated by sequential alkaline treatments of the delignified ryegrass

Table 4 Assignments of ${ }^{13} \mathrm{C}-{ }^{1} \mathrm{H}$ cross-signals in $\mathrm{HSQC}$ spectra of hemicellulosic fractions isolated by sequential alkaline extractions from the delignified ryegrass

\begin{tabular}{|c|c|c|c|c|c|c|c|c|}
\hline \multirow[t]{2}{*}{ Glycosyl } & \multicolumn{8}{|c|}{ Assignments (ppm) } \\
\hline & & 1 & 2 & 3 & 4 & $5 e q^{d}$ & $5 a x^{e}$ & $\mathrm{OCH}_{3}$ \\
\hline \multirow[t]{2}{*}{$x^{a}$} & ${ }^{13} \mathrm{C}$ & 102.4 & 73.5 & 75.0 & 76.0 & 63.2 & 63.2 & \\
\hline & ${ }^{1} \mathrm{H}$ & 4.35 & 3.17 & 3.32 & 3.60 & 3.93 & 3.21 & \\
\hline \multirow[t]{2}{*}{$u^{b}$} & ${ }^{13} \mathrm{C}$ & & 71.2 & 73.8 & & & & 59.6 \\
\hline & ${ }^{1} \mathrm{H}$ & & 3.40 & 3.61 & & & & 3.31 \\
\hline \multirow[t]{2}{*}{$A^{c}$} & ${ }^{13} \mathrm{C}$ & 109.6 & 80.2 & 78.3 & 86.5 & 61.7 & 61.7 & \\
\hline & ${ }^{1} \mathrm{H}$ & 5.25 & 3.91 & 3.63 & 4.05 & 3.73 & 3.55 & \\
\hline \multirow[t]{2}{*}{ Gal } & ${ }^{13} \mathrm{C}$ & & 69.5 & & & & & \\
\hline & ${ }^{1} \mathrm{H}$ & & 3.85 & & & & & \\
\hline
\end{tabular}

\footnotetext{
a $\mathrm{X},(1 \rightarrow 4)-\beta-\mathrm{D}-\mathrm{Xylp}$

b $U, 4-O-m e t h y l-a-D-G l c p A$

c $\mathrm{A}, \mathrm{a}-\mathrm{L}$-Araf residues

d eq, equatorial

e ax, axial
} 


\section{Conclusions}

Cellulose-rich substrates and hemicellulosic fractions were recovered from ryegrass holocellulose by sequential $\mathrm{KOH}$ extractions, respectively. With the dissolution of hemicelluloses in alkaline aqueous, the content of hemicelluloses in cellulose-rich substrates decreased from 32.7 to $19.2 \%$, and accompanying decrease of cellulose-rich substrates yields from 100 to $27.7 \%$. Alkaline extraction also removed amorphous cellulose, increasing crystallinity indexes of cellulose. The removal of hemicelluloses also reduced the physical barriers of substrates for enzyme, yielding 1.32-fold enhancement of enzymatic conversion of cellulose-rich substrates. In addition, the hemicellulosic fractions obtained from the sequential alkaline extractions contained arabinoxylans and part of $\beta$-glucans.

\section{Materials and methods Materials}

Ryegrass (35 days old) was harvested from the farm of Guangxi University. It was air dried and ground in a pulverizer. Next, the ryegrass powder was extracted with toluene-ethanol $(2: 1, \mathrm{v} / \mathrm{v})$ for $5 \mathrm{~h}$ to remove wax and chlorophyll, and employed to delignification with $\mathrm{NaClO}_{2}$ under acidic condition. The delignified residue was labeled as $R_{\text {pulp }}$ and submitted to alkaline extraction for cellulose-rich substrates and hemicellulosic fractions preparation.

\section{Sequential alkaline extractions and isolation of hemicellulosic fractions}

Sequential alkaline extractions of delignified ryegrass were conducted at a solid-liquid ratio of 1:25 (w/v) with $0.15,0.3,0.5,1.0,1.5$, and $2.5 \%(\mathrm{w} / \mathrm{v}) \mathrm{KOH}$ aqueous at $50{ }^{\circ} \mathrm{C}$ for $3 \mathrm{~h}$. After incubation, the solid fractions were filtered with a Brinell funnel, washed repeatedly with distilled water, and then oven dried at $55{ }^{\circ} \mathrm{C}$ for $16 \mathrm{~h}$. The filtrates were regulated to $\mathrm{pH} 5.5-6.0$ with acetic acid, and vaporized to $30 \mathrm{~mL}$ using a vacuum rotary evaporator. The soluble hemicellulosic fractions were obtained by the precipitation of the concentrated aqueous in three volumes of ethanol. Then, the precipitates were recovered by centrifugation and freeze-dried. All the cellulose-rich substrates and hemicellulosic fractions obtain by sequential alkaline extraction were labeled as $R_{\text {pulp }}, R_{0.15 \%}, R_{0.3 \%}$,

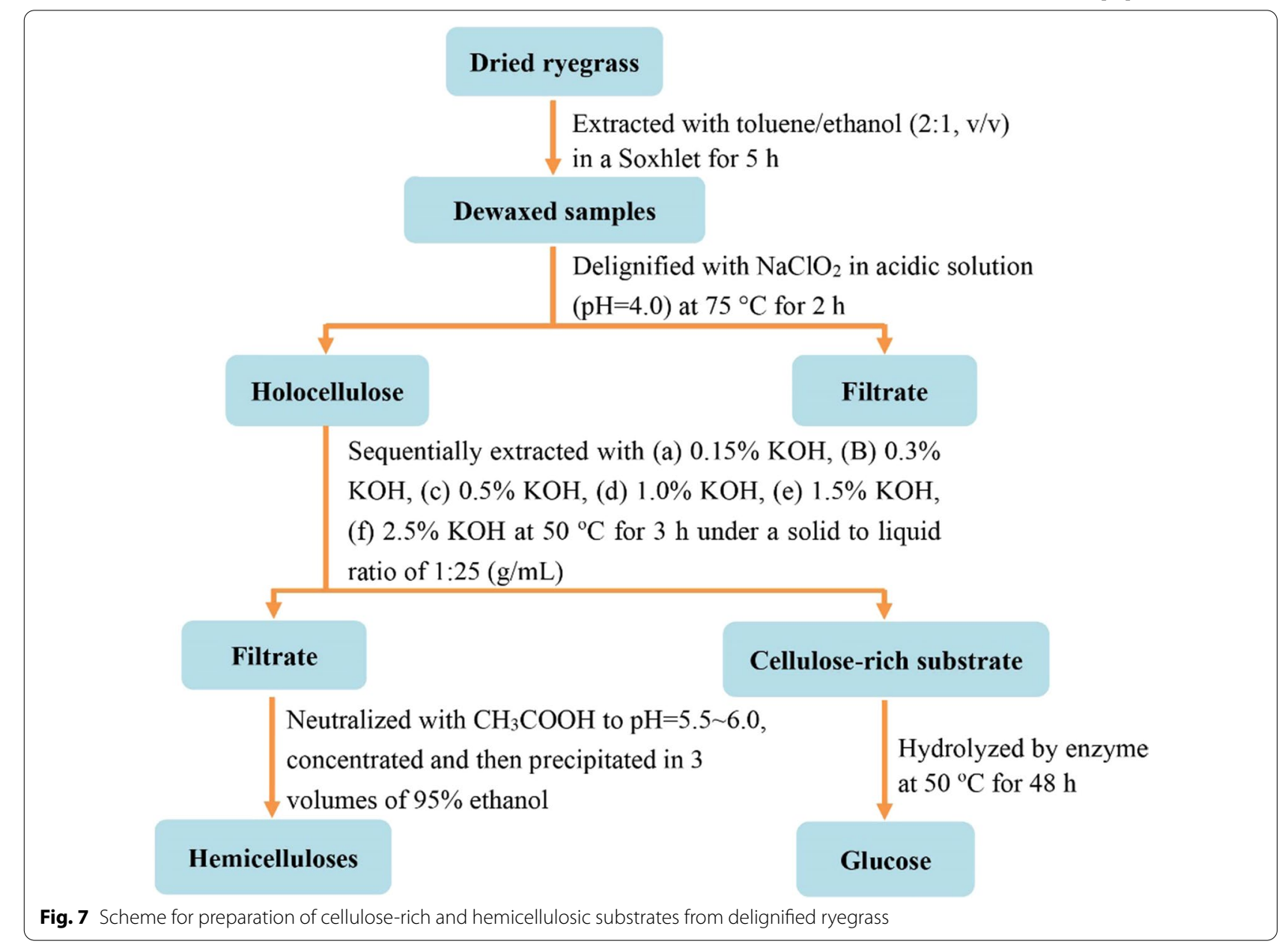


$\mathrm{R}_{0.5 \%}, \mathrm{R}_{1.0 \%}, \mathrm{R}_{2.5 \%}$, and $\mathrm{H}_{0.15 \%}, \mathrm{H}_{0.3 \%}, \mathrm{H}_{0.5 \%}, \mathrm{H}_{1.0 \%}, \mathrm{H}_{1.5 \%}$, and $\mathrm{H}_{2.5 \%}$, respectively, according to the alkali concentration. The separation scheme of cellulose-rich and hemicellulosic fractions is illustrated in Fig. 7. All the extraction experiments were repeated at least in triplicate. The average yields of cellulose-rich and hemicellulosic fractions were given, and the standard deviation (SD) of the three determination was less than $3.3 \%$ (Tables 1 and 2).

\section{Physicochemical characterization of cellulose-rich substrates and hemicellulosic fractions}

Chemical components of cellulose-rich substrates and hemicellulosic fractions from the delignified ryegrass were analyzed according to the methods of US National Renewable Energy Laboratory (NREL) [41]. Particularly, the neutral sugars and uronic acids in the samples were analyzed by high-performance anion exchange chromatography (HPAEC), and the molecular weights of hemicellulosic fractions were determined by gel permeation chromatography (GPC) [32]. The analytical experiments were conducted with three parallel performs. The mean values of the chemical composition analysis from the samples are given in Tables 1 and 2, and the SD value of the three parallel performs was less than $2.1 \%$. Meanwhile, the mean values of molecular weights of hemicellulosic fractions are given in Table 3, and the SD value of the three analysis results was less than $3040(\mathrm{~g} / \mathrm{mol})$.

FT-IR spectra of cellulose-rich substrates and hemicellulosic fractions were recorded on a Bruker Tesor 27 FT-IR spectrometer. Each substrate was mixed with spectroscopic grade potassium bromide at a concentration of $1 \%$ and ground to a fine powder. Then, the mixtures were subsequently pressed into disks using 10 tons of pressure for $1 \mathrm{~min}$. The spectra of substrates were collected at a resolution of $4 \mathrm{~cm}^{-1}$ in the wavelength range of $4000-600 \mathrm{~cm}^{-1}$.

${ }^{13} \mathrm{C}$ and 2D-HSQC NMR spectra of hemicellulosic polymers were recorded on a Bruker AVIII $400 \mathrm{MHz}$ spectrometer. For NMR spectroscopic experiments, the hemicellulosic samples $\left(80 \mathrm{mg}\right.$ for ${ }^{13} \mathrm{C}$ and $20 \mathrm{mg}$ for 2D-HSQC) were dissolved into $0.5 \mathrm{~mL} \mathrm{D}_{2} \mathrm{O}$. The ${ }^{13} \mathrm{C}$ NMR spectra were recorded at $25^{\circ} \mathrm{C}$ after 30000 scans. A $30^{\circ}$ pulse flipping angle, a $9.2 \mu$ s pulse width, and a $1.36 \mathrm{~s}$ acquisition time between scans were used. The spectra widths for HSQC were 5000 and $20000 \mathrm{~Hz}$ for the ${ }^{1} \mathrm{H}$ and ${ }^{13} \mathrm{C}$ dimensions, respectively. The number of collected complex points was 1024 for the ${ }^{1} \mathrm{H}$ dimension with a recycle delay of $5 \mathrm{~s}$. The number of transients for the HSQC spectra was 128 , and 256 time increments were always recorded in the ${ }^{13} \mathrm{C}$ dimension.

Solid-state cross-polarization/magic angle spinning $(\mathrm{CP} /$ MAS) ${ }^{13} \mathrm{C}$-NMR spectra of cellulose-rich substrates were recorded on the spectrometer mentioned above. The dried sample was packed into a $4 \mathrm{~mm}$ zirconia $\left(\mathrm{ZrO}_{2}\right)$ rotor, and measurement was performed using a $\mathrm{CP}$ pulse program with a $1 \mathrm{~ms}$ match time and a $2 \mathrm{~s}$ delay between transients. The spinning rate was $5 \mathrm{kHz}$. Calibration was done externally to the carbonyl carbon of glycine at $176 \mathrm{ppm}$.

\section{Enzymatic hydrolysis of cellulose-rich substrates}

Enzymatic hydrolysis was executed at $2 \%$ substrate $(\mathrm{w} / \mathrm{v})$ in $50 \mathrm{mM}$ sodium acetate buffer ( $\mathrm{pH} 4.8$ ) with enzyme loading of $15 \mathrm{FPU} / \mathrm{g}$ substrates using a double-layer oscillating incubator at $170 \mathrm{rpm}$ at $50{ }^{\circ} \mathrm{C}$ for $48 \mathrm{~h}$. Commercial cellulase (Cellic $\left.{ }^{\circledR} \mathrm{CTec} 2\right)$ was purchased from Novozymes (Beijing, China), which contained 100 FPU cellulase in $1 \mathrm{~mL}$ enzyme solution. During enzymatic hydrolysis, $0.2 \mathrm{~mL}$ hydrolysates were sampled periodically and analyzed by an HPAEC system. All enzymatic hydrolysis experiments were carried out in triplicate. The average values of the three results are given in Fig. 3 and the SD value was less than $3.5 \%$.

\section{Acknowledgements \\ The authors are grateful to the funding support from the Key Labora- tory for Forest Resources Conservation and Utilisation in the Southwest Mountains of China, Ministry of Education, Southwest Forestry University (KLESWFU-201807), Yunnan Provincial Department of Education (2020J0398), and National Natural Science Foundation of China (No. 31760195, 31760194).}

\section{Authors' contributions}

SFS and HYY performed the major experiments, analyzed the data, and prepared the manuscript. JY and DWW helped with the overall pretreatment experiments and analyzed the data. SNS and ZJS participated in proofreading and revising the manuscript critically. All authors read and approved the final manuscript.

\section{Funding}

Funding sources have been addressed in the Acknowledgements.

Availability of data and materials

All data generated or analyzed during this study are included in this published article.

\section{Declarations}

Ethics approval and consent to participate Not applicable.

Consent for publication

All authors consented on the publication of this work.

\section{Competing interests}

The authors declare that they have no known competing financial interests or personal relationships that could have appeared to influence the work reported in this paper.

\section{Author details}

${ }^{1}$ Key Laboratory for Forest Resources Conservation and Utilization in the Southwest Mountains of China, Ministry of Education, Southwest Forestry University, Kunming 650224, China. ${ }^{2}$ Key Laboratory of State Forestry and Grassland Administration on Highly-Efficient Utilization of Forestry Biomass Resources in Southwest China, Southwest Forestry University, Kunming 650224, China. ${ }^{3}$ Beijing Key Laboratory of Lignocellulosic Chemistry, Beijing Forestry University, Beijing 100083, China. 
Received: 7 February 2021 Accepted: 5 March 2021

Published online: 19 March 2021

\section{References}

1. Cosentino SL, Scordia D, Testa G, Monti A, Alexopoulou E, Christou M. The importance of perennial grasses as a feedstock for bioenergy and bioproducts. Perennial Grasses for Bioenergy and Bioproducts: Elsevier; 2018. p. $1-33$

2. Mohapatra S, Mishra C, Behera SS, Thatoi H. Application of pretreatment, fermentation and molecular techniques for enhancing bioethanol production from grass biomass-a review. Renew Sust Energ Rev. 2017;78:1007-32

3. Tye YY, Lee KT, Abdullah WNW, Leh CP. The world availability of non-wood lignocellulosic biomass for the production of cellulosic ethanol and potential pretreatments for the enhancement of enzymatic saccharification. Renew Sust Energ Rev. 2016;60:155-72.

4. Wongwatanapaiboon J, Kangvansaichol K, Burapatana V, Inochanon R, Winayanuwattikun P, Yongvanich T, Chulalaksananukul W. The potential of cellulosic ethanol production from grasses in Thailand. J Biomed Biotechnol. 2012;303748:1-10

5. Sharma H, Carmichael E, Muhamad M, Mccall D, Andrews F, Lyons G, Mcroberts WC, Hornsby PR. Biorefining of perennial ryegrass for the production of nanofibrillated cellulose. RSC Adv. 2012;2(16):6424-37.

6. Kim JS, Lee YY, Kim TH. A review on alkaline pretreatment technology for bioconversion of lignocellulosic biomass. Bioresource Technol. 2016:199:42-8.

7. Kumari D, Singh R. Pretreatment of lignocellulosic wastes for biofuel production: a critical review. Renew Sust Energ Rev. 2018;90:877-91.

8. Ren JL, Sun RC, Liu CF, Lin L, He BH. Synthesis and characterization of nove cationic SCB hemicelluloses with a low degree of substitution. Carbohyd Polym. 2007:67(3):347-57.

9. Ying WJ, Shi ZJ, Yang HY, Xu GF, Zheng ZF, Yang J. Effect of alkaline lignin modification on cellulase-lignin interactions and enzymatic saccharification yield. Biotechnol Biofuels. 2018;11(1):1-13.

10. Sun RC, Tomkinson J, Mao FC, Sun XF. Physicochemical characterization of lignins from rice straw by hydrogen peroxide treatment. J Appl Polym Sci. 2001;79(4):719-32.

11. Hu F, Ragauskas A. Pretreatment and lignocellulosic chemistry. Bioenerg Res 2012:5(4):1043-66

12. Zheng Y, Shi J, Tu M, Cheng YS. Principles and development of lignocellulosic biomass pretreatment for biofuels, vol. 2. New York: Elsevier; 2017. p. $1-68$

13. He YF, Pang YZ, Liu YP, Li X, Wang KS. Physicochemical characterization of rice straw pretreated with sodium hydroxide in the solid state for enchancing biogas production. Energy Fuels. 2008;22:2775-81.

14. Kricka W, Fitzpatrick J, Bond U. Challenges for the production of bioethanol from biomass using recombinant yeasts, vol. 92. New York: Elsevier; 2015. p. 89-125.

15. Timell TE. Recent progress in the chemistry of wood hemicelluloses. Wood Sci Technol. 1967;1(1):45-70

16. Willför S, Sundberg A, Hemming J, Holmbom B. Polysaccharides in some industrially important softwood species. Wood Sci Technol. 2005;39(4):245-57

17. Willför S, Sundberg A, Pranovich A, Holmbom B. Polysaccharides in some industrially important hardwood species. Wood Sci Technol. 2005:39(8):601-17.

18. Li ZQ, Pan XJ. Strategies to modify physicochemical properties of hemicelluloses from biorefinery and paper industry for packaging material. Rev Environ Sci Bio. 2018;17(1):47-69.

19. Chen X, Cao XF, Sun SN, Yuan TQ, Shi QT, Zheng L, Sun RC. Evaluating the production of monosaccharides and xylooligosaccharides from the prehydrolysis liquor of kraft pulping process by acid and enzymatic hydrolysis. Ind Crop Prod. 2018;124:906-11.

20. Wen JL, Xiao LP, Sun YC, Sun SN, Xu F, Sun RC, Zhang XL. Comparative study of alkali-soluble hemicelluloses isolated from bamboo (Bambusa rigida). Carbohyd Res. 2011;346(1):111-20.

21. Qing Q, Wyman CE. Supplementation with xylanase and $\beta$-xylosidase to reduce xylo-oligomer and xylan inhibition of enzymatic hydrolysis of cellulose and pretreated corn stover. Biotechnol Biofuels. 2011;4(1):1-12.
22. Bañuelos JA, Velázquez-Hernández I, Guerra-Balcázar M, Arjona N. Production, characterization and evaluation of the energetic capability of bioethanol from Salicornia Bigelovii as a renewable energy source. Renew Energ. 2018;123:125-34.

23. Yang HY, Chen Q, Wang K, Sun RC. Correlation between hemicellulosesremoval-induced hydrophilicity variation and the bioconversion efficiency of lignocelluloses. Bioresour Technol. 2013;147:539-44.

24. Rezende CA, de Lima MA, Maziero P, Deazevedo ER, Garcia W, Polikarpov I. Chemical and morphological characterization of sugarcane bagasse submitted to a delignification process for enhanced enzymatic digestibility. Biotechnol Biofuels. 2011;4(1):54

25. Sun SN, Sun SL, Cao XF, Sun RC. The role of pretreatment in improving the enzymatic hydrolysis of lignocellulosic materials. Bioresour Technol. 2016;199:49-58.

26. Jiang W, Xu J. A novel stepwise pretreatment on corn stalk by alkali deacetylation and liquid hot water for enhancing enzymatic hydrolysis and energy utilization efficiency. Bioresour Technol. 2016;209:115-24.

27. Foston M. Advances in solid-state NMR of cellulose. Curr Opin Biotech. 2014;27:176-84

28. Atalla RH, Vanderhart DL. The role of solid state $13 \mathrm{C}$ NMR spectroscopy in studies of the nature of native celluloses. Solid State Nucl Mag. 1999;15(1):1-19.

29. Phitsuwan P, Sakka K, Ratanakhanokchai K. Structural changes and enzymatic response of Napier grass (Pennisetum purpureum) stem induced by alkaline pretreatment. Bioresour Technol. 2016;218:247-56.

30. Kataria R, Woods T, Casey W, Cerrone F, Davis R, O'Connor K, Ruhal R, Babu R. Surfactant-mediated hydrothermal pretreatment of ryegrass followed by enzymatic saccharification for polyhydroxyalkanoate production. Ind Crop Prod. 2018:111:625-32

31. Castoldi R, Correa VG, de Morais GR, de Souza CG, Bracht A, Peralta RA, Moreira RFP, Peralta RM. Liquid nitrogen pretreatment of eucalyptus sawdust and rice hull for enhanced enzymatic saccharification. Bioresour Technol. 2017:224:648-55.

32. Peng F, Ren JL, Xu F, Bian J, Peng P, Sun RC. Comparative study of hemicelluloses obtained by graded ethanol precipitation from sugarcane bagasse. J Agr Food Chem. 2009:57(14):6305-17.

33. Wen JL, Sun YC, Xu F, Sun RC. Fractional Isolation and Chemical Structure of Hemicellulosic Polymers Obtained from Bambusa rigida Species. J Agr Food Chem. 2010;58(21):11372-83.

34. Yang HY, Song XL, Yuan TQ, Xu F, Sun RC. Fractional characterization of hemicellulosic polymers isolated from Caragana korshinskii Kom. Ind Eng Chem Res. 2011:50(11):6877-85.

35. Glasser WG, Kaar WE, Jain RK, Sealey JE. Isolation options for non-cellulosic heteropolysaccharides (HetPS). Cellulose. 2000;7(3):299-317.

36. Chesson A, Gordon AH, Lomax JA. Substituent groups linked by alkali-labile bonds to arabinose and xylose residues of legume, grass and cereal straw cell walls and their fate during digestion by rumen microorganisms. J Sci Food Agric. 1983;34(12):1330-40

37. Peng F, Bian J, Ren JL, Peng P, Xu F, Sun RC. Fractionation and characterization of alkali-extracted hemicelluloses from peashrub. Biomass Bioenergy. 2012;39:20-30.

38. Vignon MR, Gey C. Isolation, ${ }^{1} \mathrm{H}$ and ${ }^{13} \mathrm{C}$ NMR studies of (4-O-methyl-Dglucurono)-D-xylans from luffa fruit fibres, jute bast fibres and mucilage of quince tree seeds. Carbohyd Res. 1998;307(1-2):107-11.

39. Xu F, Geng ZC, Sun JX, Liu CF, Ren JL, Sun RC, Fowler P, Baird MS. Fractional and structural characterization of hemicelluloses from perennial ryegrass (Lolium perenne) and cocksfoot grass (Dactylis glomerata). Carbohyd Res. 2006;341(12):2073-82

40. Xu F, Sun JX, Geng ZC, Liu CF, Ren JL, Sun RC, Fowler P, Baird M. Comparative study of water-soluble and alkali-soluble hemicelluloses from perennial ryegrass leaves (Lolium peree). Carbohyd Polym. 2007;67(1):56-65.

41. Sluiter A, Hames B, Ruiz R, Scarlata C, Sluiter J, Templeton D, Crocker D. Determination of structural carbohydrates and lignin in biomass. Lab Anal Proced. 2008:1617(1):1-16.

\section{Publisher's Note}

Springer Nature remains neutral with regard to jurisdictional claims in published maps and institutional affiliations. 